\title{
ANALISIS PREFERENSI KONSUMEN TERHADAP PEMBELIAN TEH DI KABUPATEN SUKOHARJO
}

\author{
Febriana Ramadhani ${ }^{1}$, Umi Barokah ${ }^{1}$, Joko Sutrisno ${ }^{1}$ \\ ${ }^{1)}$ Fakultas Pertanian, Jurusan Agribisnis, Unversitas Sebelas Maret, JI. Ir. Sutami No. 36A, Surakarta, email: \\ febrianaramadhanif@gmail.com
}

\begin{abstract}
Abstrak
Penelitian ini bertujuan untuk mengetahui preferensi konsumen terhadap atribut yang ada pada teh seduh dan teh celup, serta atribut yang paling dipertimbangkan saat pembelian teh. Peneltian ini dilakukan di tiga kecamatan di Kabupaten Sukohajo yaitu Kecamatan Kartasura (kota), Sukoharjo (sub urban) dan Weru (desa). Penentuan responden dengan menggunakan metode accidental sampling sebanyak 96 orang. Pengumpulan data dilakukan pada bulan April-Mei 2018. Data dianalisis menggunakan analisis chi-square dan analisis multi atribut fishbein. Penelitian menunjukkan bahwa ada perbedaan preferensi konsumen dalam pembelian teh. Hasil analisis multi atribut fishbein menunjukka bahwa atibut yang paling dipertimbangkan oleh konsumen dalam keputusan pembelian untuk teh seduh adalah rasa, sedangkan untuk teh celup adalah kepraktisan.
\end{abstract}

Kata kunci: teh celup, teh seduh, preferensi konsumen

\begin{abstract}
This research aims to find out the brewed tea and teabag attributes to determine consumer preferences and to know the attributes of brewed tea and teabag which most considered when purchasing tea. This research was conducted in three sub-districts in Sukoharjo Regency that are Kartasura sub-district (urban), Sukoharjo (sub urban) and Weru (rural). Respondents were choosen by accidental sampling method of 96 people. Data collection was carried out in April - Mei 2018. Data were analyzed using chi-square analisys and fishbein multiattribute analisys. The research showed that there are differences in consumer preferences in the purchase of tea. The results of the multi-attribute fishbein analysis showed that the attributes most considered by consumers in purchasing decisions for brewed tea are taste, while in teabags is practicality.
\end{abstract}

Keywords: teabag, brewed tea, consumer preferences

\section{PENDAHULUAN}

Teh merupaka salah satu bahan minuman yang dikonsumsi sehari-hari oleh masyarakat. Di Provinsi Jawa Tengah, teh merupakan minuman yang paling banyak dikonsumsi dibanding dengan jenis minuman serbuk lainnya yaitu dengan proporsi sebesar 49,80\% (BPPK, 2014). Kandungan kafein, bioflavonoid, essential oil dan polifenol pada teh memberi manfaat bagi tubuh. Teh memiliki kandungan zat bioaktif go vonoid yang menjadikan rasa teh menjadi khas (Hartoyo, 2003). Senyawa kimia tersebut banyak terkandung di bagian daun yang bermanfaat memberi rasa segar, dapat memulihkan kesehatan badan dan terbukti tidak menimbulkan dampak negatif (Towaha dan Balitri, 2013).

Data dari BPS (2015) menunjukkan jumlah penduduk Kabupaten Sukoharjo semakin meningkat, diimbangi dengan banyaknya ragam teh yang dijual di pasaran serta adanya masyarakat dari berbagai segmen sehingga menimbulkan perbedaan preferensi konsumen terhadap pembelian produk teh. Preferensi konsumen merupakan kesukaan, pilihan atau sesuatu hal yang lebih disukai konsumen (Munandar, et al. 2012). Memahami konsumen merupakan informasi pasar yang penting bagi produsen teh untuk merencanakan, mengembangkan, dan memasarkan 
produknya dengan baik untuk memberikan rekomendasi pada strategi pemasaran yang lebih efektif sesuai dengan kebutuhan konsumen (Ikmanila, et al. 2018). Pengukuran selera konsumen terhadap pembelian teh dapat diukur dengan cara melihat atribut dalam teh tersebut (Munandar, Udin \& Amelia, 2012). Penelitian terdahulu yang dilakukan oleh Sakthirama (2016) pada teh organik bahwa preferensi dan sikap konsumen teh dilihat dari atribut produk dan karakteristik demografis. Penelitian Larasati dan Isutarti (2017) menunjukkan bahwa lima atribut penting dari teh murbei adalah warna, aroma, rasa, kemasan dan harga. Sejalan dengan Harjono dan Utami (2017) penelitian pada produk minuman dilihat pada atribut kemasan, volume, dan harga. Atribut kepraktisan juga penting untuk mengukur preferensi pada teh celup (Ikmanila, et al. 2018).

Konsumen lebih memilih produk teh dengan mempertimbangkan kwalitasnya karena memprioritaskan kesehatan walaupun dengan harga yang lebih tinggi (Snehaghai \& Ramawat, 2016). Penelitian Poornima dan Ramesh (2016) juga menunjukkan bahwa konsumen memilih produk minuman berdasarkan kualitas dan rasa dari pada harga.

Tujuan penelitian ini untuk mengetahui preferensi dan atribut yang paling dipertimbangkan konsumen terhadap pembelian teh di Kabupaten Sukoharjo. Teh yang banyak dikonsumsi rumah tangga dalam memenuhi kebutuhan sehari-hari di Kabupaten Sukoharjo adalah teh seduh dan teh celup. Berbagai jenis atribut yang melekat pada teh juga beragam. Atribut pada teh seduh meliputi rasa, warna, aroma, dan ukuran. Atribut rasa dibedakan menjadi rasa pahit, sepat sangat pahit, sepat sedikit pahit dan sepat. Atribut warna dibedakan menjadi warna merah pekat kehitaman, coklat kehitaman, merah kecoklatan, dan merah kekuningan. Atribut aroma dibedakan menjadi non aromatik, sedikit harum, dan sangat harum. Sedangkan atribut ukuran dibedakan menjadi ukuran 80 gram, 40 gram, dan 10 gram. Atribut teh celup meliputi rasa, warna, aroma, ukuran, kepraktisan, bentuk kantong, dan jenis kemasan. Sama pada teh seduh, atribut rasa pada teh celup meliputi rasa pahit, sepat sangat pahit, sepat sedikit pahit dan sepat. Atribut warna dibedakan menjadi warna merah pekat kehitaman, coklat kehitaman, merah kecoklatan, dan merah kekuningan. Atribut aroma dibedakan menjadi non aromatik, sedikit harum, dan sangat harum. Atribut ukuran dibedakan menjadi kemasan isi 100 gram, 60 gram, 50 dan 8 gram. Atribut kepraktisan dapat dilihat dari teh mudah disimpan dan teh mudah disajikan. Atribut bentuk kantong meliputi bentuk kantong bundar dan kantong kotak, sedangkan jenis kemasan meliputi kemasan kardus dan kemasan plastik.

Kebaruan penelitian ini yaitu melihat preferensi konsumen pada masyarakat yang mengkonsumsi teh seduh sekaligus teh celup dengan melihat masing-masing atribut yang dimiliki. Penelitian ini dilakukan di tiga Kecamatan yang mewakili daerah urban, sub urban, dan desa. Tujuan penelitian ini untuk mengetahui preferensi konsumen berdasarkan atribut teh yang dimiliki.

\section{METODE}

Pengambilan data dilakukan pada bulan April sampai Mei 2018. Penelitian dilakukan di tiga kecamatan yaitu Kartasura, Sukoharjo dan Weru dengan pertimbangan yang mewakili daerah urban, sub urban, dan pedesaan di Kabupaten Sukoharjo. Menurut Weber dalam Sukirno dan Harianto (2017) daerah kota merupakan daerah yang masyarakatnya telah berkembang bergeser dari berfikir tradisional menjadi pola berpikir rasional, praktis dan modern. Daerah sub 
urban merupakan wilayah bagian dari kota namun menampakkan kenampakan desa dan juga kota secara bersamaan. Menurut Landis dalam Rahardjo (2017) daerah desa merupakan suatu lingkungan yang penduduknya memiliki hubungan yang akrab dan serta informal di antara sesama warganya serta tergantung pada pertanian.

Pengambilan sampel dengan acidental sampling. Penentuan sampel populasi yang tidak diketahui maka menggunakan confident level sebesar 95\% dan besarnya sampel dapat diketahui menggunakan rumus Lemeshow yaitu sebanyak 96 responden (Rendy dan Devie, 2013). Analisis data yang dilakukan adalah analisis deskriptif, untuk mengetahui preferensi konsumen terhadap atribut teh menggunakan analisis Chi-square dan diolah dengan bantuan SPSS 16 (Simamora, 2004).

$$
\mathrm{X}^{2}=\sum_{i=1}^{k} \frac{(f o-f e)^{2}}{f e}
$$

Penentuan atribut yang paling dipertimbangkan saat pembelian teh (sikap konsumen) menggunakan metode analisis multiatribut Fishbein (Maryani, Kristiana \& Lesatari, 2017).

$$
\mathrm{A} 0=\sum_{i=1}^{n} \text { bi. } e i
$$

\section{HASIL DAN PEMBAHASAN}

\section{Uji Instrumen Penelitian}

Pengujian instrumen penelitian dilakukan dengan uji validitas dan reliabilitas pada 30 responden. Hasil pengujian diketahui bahwa atribut rasa, warna, aroma dan ukuran pada teh seduh nilai $\mathrm{R}$ hitung lebih besar dari $R$ tabel berarti semua instrument pertanyaan pada teh seduh valid. Atribut bentuk kantong teh celup tidak valid, sehingga dikeluarkan dari penelitian. Atribut yang valid diuji reliabilitasnya. Hasil dari pengujian reliabilitas menunjukkan bahwa nilai Cronbanc's Alpha pada teh seduh sebesar 0,479 dan pada teh seduh sebesar 0,646 sehingga kuesioner pada penelitian ini reliabel. Pengujian instrumen dari teh seduh maupun teh celup terbukti valid dan reliabel. Butir pertanyaan dapat digunakan dalam penelitian.

\section{Perilaku Beli Konsumen}

Alasan responden mengkonsumsi teh paling banyak dinikmati untuk kesegaran yaitu sebesar $61 \%$. Konsumsi teh baik disajikan hangat maupun dingin, mereka merasa setelah mengkonsumsi teh tubuh menjadi lebih segar. Menurut Anjarsari (2016) terdapat senyawa komplek yang paling penting didalam teh, yaitu katekin yang bermanfaat bagi kesehatan.

Konsumen paling banyak membeli teh di warung kelontong, yaitu sebesar $71 \%$ responden dengan alasan tempat pembelian dekat dengan rumah sehingga lebih mudah untuk mendapatkannya. Konsumen paling banyak dengan frekuensi 0-1 kali dalam setiap bulannya untuk teh seduh dengan persentase $45 \%$ sedangkan pada teh celup sebanyak $69 \%$. Sebagian besar responden membeli teh seduh antara 101-200 gram perbulan, yaitu sebayak $51 \%$ responden dan $39 \%$ pada teh celup. $57 \%$ responden.

\section{Preferensi Konsumen Terhadap Atribut Teh}

Hasil analisis chi-square mengenai kategori atribut teh yang menjadi preferensi konsumen dapat dilihat pada Tabel 3 dan 4 . Perhitungan chi-square menunjukkan hasil yang signifikan pada atribut yang diteliti baik teh seduh maupun teh celup. Berarti terdapat perbedaan preferensi konsumen terhadap pembelian teh di Kabupaten Sukoharjo. Preferensi konsumen dapat diketahui dengan melihat kategori atau kriteria atribut yang paling banyak dipilih oleh konsumen.

Konsumen teh seduh dan teh celup baik pada daerah urban, sub urban maupun pedesaan paling banyak lebih menyukai rasa teh sepat sedikit pahit karena dapat 
memberikan rasa yang enak serta menyegarkan saat dikonsumsi dan merupakan indikator rasa yang paling baik pada teh. Teh mengandung alkaloid kafein yang bersama-sama dengan polifenol akan membentuk rasa yang menyegarkan (Manik, Rusmarili \& Limbong, 2015). Responden mencampur racikan teh seduh mulai dari dua hingga empat campuran merek teh. Responden khususnya dari daerah desa juga mencampurkan teh seduh dan teh celup untuk disajikan secara bersama.

Konsumen yang lebih menyukai rasa pahit alasannya karena sudah terbiasa sejak kecil di keluarganya apabila meramu teh yang memiliki rasa pahit. Responden yang lebih menyukai rasa sepat yang sangat pahit karena rasa tersebut lebih terasa dilidah konsumen. Sedangkan konsumen yang menyukai rasa sepat, karena konsumen yang tidak terlalu menggemari teh. Konsumen tetap mengkonsumsi teh walaupun hanya sedikit untuk memenuhi rasa keinginan mereka. Menurut responden, rasa pada teh seduh lebih enak dari pada teh celup. Tetapi konsumen juga mengkonsumsi teh celup walaupun rasanya tidak semantap teh seduh. Menurut responden teh seduh yang dijual di Kabupaten Sukoharjo juga belum menghasilkan rasa yang sesuai dilidah konsumen sehingga harus ada pencampuran beberapa merek teh untuk menghasilkan rasa sedap sesuai dengan kesukaan konsumen.

Konsumen pada daerah urban dan pedesaan paling banyak lebih menyukai warna coklat kehitaman sedangkan pada daerah sub urban paling banyak menyukai merah kecoklatan pada teh seduh. Warna teh celup baik konsumen di daerah urban, sub urban, maupun pedesaan paling banyak menyukai warna merah kecoklatan. Alasan menyukai warna tersebut karena warnanya bagus serta menurut konsumen warna tersebut merupakan warna yang paling baik pada teh. Konsumen kurang menyukai warna merah pekat kehitaman dan coklat kehitaman karena warna tersebut identik dengan rasa pahit yang juga tidak disukai oleh konsumen. Warna teh merah kekuningan juga kurang diminati oleh konsumen, karena menurut responden warnanya yang bening sehingga kurang menarik dan rasa tehnya kurang terasa. Penelitian ini sejalan dengan pernyataan Tanti \& Somantri (2011) bahwa teh yang baik dikonsumsi tidak terlalu pekat, karena semakin pekat warna teh maka kadar antioksidannya akan hilang dan kadar kafein akan banyak terektrasi. Sejalan dengan penelitian Snehaghai \& Ramawat (2016) bahwa konsumen lebih mementigkan kualitas daripada harga dalam membeli teh.

Konsumen pada daerah urban, sub urban, maupun pedesaan paling banyak lebih menyukai aroma sedikit harum untuk teh seduh sedangkan untuk teh celup pada daerah sub urban dan desa juga paling banyak lebih menyukai aroma sedikit harum tetapi di daerah urban paling banyak menyukai teh yang non aromatik. Konsumen tidak menyukai aroma yang sangat harum karena menurut konsumen tidak enak saat dikonsumsi.

Konsumen memilih ukuran sesuai dengan jumlah kebutuhan konsumsi pada anggota rumah tangganya. Konsumen lebih menyukai teh seduh dengan ukuran 40 gram baik pada daerah urban, sub urban, maupun desa. Sedangkan pada teh celup, konsumen daerah urban dan sub urban lebih menyukai ukuran 8 gram tetapi daerah desa lebih menyukai ukuran 50 gram. Ukuran 40 gram pada teh seduh menurut konsumen merupakan ukuran standar, tidak terlalu banyak dan tidak terlalu sedikit. Sehingga dengan ukuran yang standar dapat digunakan untuk mencukupi kebutuhan sehari-hari di rumah tangganya. Baik untuk 
konsumsi dirumah maupun untuk bekal bekerja maupun kesekolah. Konsumen daerah urban dan sub urban lebih menyukai ukuran 8 gram karena cepat habis untuk dikonsumsi. Konsumen menginginkan kondisi teh celup yang selalu baru untuk menghindari perubahan kualitas teh apabila tidak cepat habis. Tempat pembelian teh daerah tersebut juga mudah dijangkau dari rumah sehingga akan lebih mudah untuk mendapatkan teh yang diinginkan. Konsumen daerah pedesaan lebih menyukai ukuran 50 gram karena daerah tersebut masih sulit untuk mendapatkan teh celup. Masih jarang ditemukan tempat yang menjual teh celup, sehingga mereka lebih memilih ukuran tersebut sehingga dapat digunakan dalam jangka waktu yang lebih lama.

Kepraktisan pada teh celup, konsumen baik dari daerah urban, sub urban, maupun desa lebih menyukai teh celup yang mudah dalam penyajiaanya. teh celup tidak perlu memakai banyak perabot dapur seperti alat penyaring dan tempat penyeduh seperti yang digunakan dalam penyajian teh seduh. Selain itu, pada teh celup tidak menghasilkan ampas yang harus dibuang seperti pada teh seduh.

Konsumen pada daerah urban lebih menyukai teh celup dengan kemasan plastik karena lebih praktis. Selain itu kemasana plastik juga identik dengan kemasan sachet yang isinya lebih sedikit, jadi lebih cepat habis dan tidak terlalu lama dalam penyimpanan. Sedangkan konsumen pada daerah sub urban dan desa lebih menyukai kemasan kardus dengan alasan lebih rapi dan isi tidak mudah terkontaminasi saat penyimpanan, karena kemasan kardus mudah untuk ditutup kembali.

\section{Atribut yang Paling Dipertimbangkan Konsumen dalam Pembelian Teh}

Atribut yang paling dipertimbangkan konsumen dalam pembelian teh dilihat dari hasil analisis Fishbein, yaitu dengan melihat nilai indeks sikap konsumen yang dibentuk dari keyakinan dan evaluasi konsumen terhadap atribut the (Tabel 5). Atribut yang dipertimbangkan konsumen pada teh seduh dan teh celup berbeda. Konsumen paling mempertimbangkan atribut rasa saat pembelian teh seduh dengan indek sikap sebesar 20,33. Sedangkan pada teh celup, konsumen paling mempertimbangkan atribut kepraktisan dengan indek sikap 18,67.

Rasa merupakan atribut pertama yang dipertimbangkan konsumen dalam pengambilan keputusan pembelian teh seduh di Kabupaten Sukoharjo. Konsumen cenderung memilih rasa sebagai pertimbangan pertama karena tujuan konsumen dalam membeli teh seduh adalah untuk dikonsumsi atau dinikmati rasanya. Penelitian ini sejalan dengan penelitian Rahardjo (2017) bahwa atribut rasa merupakan atribut yang paling dipertimbangkan saat pembelian teh. Penelitian ini juga sejalan dengan penelitian Hidayat (2001) bahwa atribut rasa merupakan atribut yang paling dipertimbangkan saat pembelian teh dan tidak terlalu mementingkan atribut harga.

Konsumen dalam membeli teh celup yang paling utama dipertimbakan adalah atribut kepraktisan. Konsumen mempertimbangkan atribut tersebut karena untuk mempermudah dalam penyajian teh. Sejalan dengan Ikmanila (2018) bahwa proses keputusan pembelian teh celup adalah kebutuhan. Alasan utama konsumen membeli dan mengkonsumsi teh celup yaitu karena praktis dan mudah dikonsumsi.

\section{KESIMPULAN}

Terdapat perbedaan preferensi konsumen terhadap pembelian teh di Kabupaten Sukoharjo, baik pada teh seduh maupun teh celup. Atribut yang paling dipertimbangkan saat pembelian pada teh 
seduh adalah rasa sedangkan pada teh celup adalah kepraktisan.

\section{DAFTAR PUSTAKA}

Anjarsari IRD. 2016. Katekin Teh Indonesia: Prospek dan Manfaatnya. Jurnal Kultivasi. 15 (2): 99-106. https://journals.unpad.ac.id/kultivasi/a rticle/viewFile/11871/5585

BPPK. 2014. Survei Makanan Individu Provinsi Jawa Tengah 2014. http://pusat2.litbang.depkes.go.id/

BPS. 2015. Pemerataan Pendapatan dan Pola Konsumsi Penduduk Jawa Tengah 2015. https://jateng.bps.go.id

Hartoyo A. 2003. Teh dan Khasiatnya Bagi Kesehatan. Kanisius. Yogyakarta.

Harjono SW, Utami CW. 2017. Consumer Preferences for Attributes of Interest of Honey Products. Asian Business Research. 2 (3): 26-32.

Hidayat, AR. 2001. Analisis Preferensi Konsumen Terhadap Teh di Lingkungan Mahasiswa Universitas Jember. Skripsi. http://www.repository.unej.ac.id.

Ikmanila Regina, Mukson, Setiyawan Hery. 2018. Analisis Preferensi Konsumen Rumah tangga terhadap The Celup di Kota Semarang. Jurnal Optimum. 8 (1): 1-14.

Larasati, A., \& Issutarti. (2017). The Analysis of Consumer Preferences on Mulberry Leaves Tea as An Antioxidant-Enriched Product. Advances in Economics, Business and Management Research, 1 (40), 40-51. https:// researchgate.net/publication/3220441 11.

Maryani, H., Kristiana, L., Lestari, W. (2017). Analisis Multiatribut Fishbein terhadap Jamu Saintifik (Studi Kasus di Balai Kesehatan Tradisional Masyarakat Makasar dan Puskesmas
Colomadu I Karanganyar). Media Litbangkes, $27 \quad$ (2), 89-98. https://ejournal.litbang.depkes.go.id/i ndex.php

Munandar, JM. Udin, F. Amelia, M. (2012). Analisis Faktor yang Mempengaruhi Preferensi Konsumen Produk Air Minum Dalam Kemasan di Bogor. $J$ Teknologi Industri Pertanian IPB, 3 (3), 97-107. http://journal.ipb.ac.id/index.php/jurna Itin/article/.

Manik, DT., Rusmarilin, H., \& Limbong, LN. (2015). Mempelajari Pengaruh Lama Pelayuan dan Penambahan Teh Daun Sirsak terhadap Mutu Teh Hitam. J. Rekayasa Pangan dan Pertanian, 3 (1), 14-18. http://download.portalgaruda.org/artic le

Poornima S, Ramesh L. 2016. Consumer Preferenvce Toward aavin Milk and Milk Product. International Journal of Current Multidisciplinary Studies. 2 (8): 384-389. https://journalijcms.com/.../consumerpreference-towards-aavin-milk.

Qomariyah N, Santoso I, Effendi M. 2014. "Analisis Sikap Konsumen dan Kinerja Atribut Kopi Bubuk Sido Luhur, Kota Malang". Jurnal Industria. 3 (1): 5361.https://industria.ub.ac.id/index.php /industri/article/download/155/335

Rahardjo SA. 2017. Analisis Atribut yang Menjadi Preferensi Konsumen dalam Memilih Produk HOMDS Teh Hijau. PERFRMA: Jurnal Manajemen dan Start-Up Bisnis. 1 (6): 739-745. https://journal.uc.ac.id/index.php/perf orma/article/view/402

Rendy dan Devie. 2013. "Analisa Pengaruh Activity Based Costing terhadap Keunggulan Bersaing dan Kinerja Organisasi". Business Accounting Review. 1 (2): $\quad$ 61-71. https://publication.petra.ac.id/index.p hp/akutansi-bisnis/article/view/578. 
Sakthirama V. 2016. Consumer Preferences for Organic Tea an Empirical Analysis. Namex International Journal of Management Research. 6 (1): $96-100$.

Simamora B. 2004. Panduan Riset Perilaku Konsumen. Jakarta: PT Gramedia Pustaka Utama.

Snehaghai dan Ramawat N. 2016. A Study of Consumer Perception and Preferences Toward Organic Tea in Delhi-NCR. IMPACT: International Journal of Research in Applied, Natural and Social Sciences. 4 (7): 101-110. http://oaji.net/articles/2016/49114701 40795.

Sukirno FS, Harianto S. 2017. "Pergeseran Gaya Hidup Masyarakat Sub Urban Area di Kota Mojokerto". Jurnal Paradigma. $\quad 5 \quad$ (1): 1-9. https://jurnalmahasiswa.unesa.ac.id/i ndex.php/paradigma/article/view/181 02.

Towaha J, Balittri. 2013. Kandungan Senyawa Kimia pada Daun Teh (Camelia sinensis). Warta Penelitian dan Pengembangan Tanaman Industri. 19 (3): 12-16. 


\section{LAMPIRAN}

Tabel 1. Hasil Uji Validitas Teh Seduh dengan Rumus Bivarate Pearson

\begin{tabular}{lcccc}
\hline \multirow{2}{*}{ Atribut } & \multicolumn{2}{c}{ Teh Seduh } & \multicolumn{2}{c}{ Teh Celup } \\
\cline { 2 - 5 } & r hitung & Keterangan & r hitung & Keterangan \\
\hline Rasa & 0,909 & Valid & 0,811 & Valid \\
Warna & 0,850 & Valid & 0,771 & Valid \\
Aroma & 0,512 & Valid & 0,510 & Valid \\
Ukuran & 0,708 & Valid & 0,562 & Valid \\
Kepraktisan & - & - & 0,454 & Valid \\
Bentuk & - & - &.$a$ & Tidak Valid \\
Kantong & - & - & 0,535 & Valid \\
Jenis & - & & & \\
Kemasan & \multicolumn{5}{c}{ Sumber : Analisis Data Primer, 2018 } \\
\hline \multicolumn{5}{c}{}
\end{tabular}

Tabel 2. Hasil Uji Reliabilitas Teh Seduh dengan Metode Cronbanc's Alpha

\begin{tabular}{lccc}
\hline Jenis Teh & $\begin{array}{c}\text { Cronbach's } \\
\text { Alpha }\end{array}$ & N of Items & Keterangan \\
\hline Seduh & 0,749 & 4 & Reliabel \\
Celup & 0,646 & 6 & Reliabel \\
\hline \multicolumn{4}{c}{ Sumber: Analisis Data Primer, 2018 }
\end{tabular}

Tabel 3. Hasil Analisis Chi-Square Atribut Teh Seduh di Kabupaten Sukoharjo Tahun 2018

\begin{tabular}{lcccrcc}
\hline \multirow{2}{*}{ Atribut Teh } & \multicolumn{3}{c}{ Teh Seduh } & \multicolumn{3}{c}{ Teh Celup } \\
\cline { 2 - 7 } & $\mathbf{X}_{\text {hitung }}$ & $\mathbf{X}_{\text {tabel }}$ & Keterangan & $\mathbf{X}_{\text {hitung }}$ & $\mathbf{X}_{\text {tabel }}$ & Keterangan \\
\hline Rasa & 29,583 & 7,815 & Signifikan & 43,583 & 7,815 & Signifikan \\
Warna & 15,583 & 7,815 & Signifikan & 19,500 & 7,815 & Signifikan \\
Aroma & 17,062 & 5,992 & Signifikan & 27,062 & 5,992 & Signifikan \\
Ukuran & 75,000 & 5,992 & Signifikan & 14,833 & 7,815 & Signifikan \\
Kepraktisan & - & - & - & 18,375 & 3,842 & Signifikan \\
Jenis Kemasan & - & - & - & 8,167 & 3,842 & Signifikan \\
\hline Sumber : Analisis Data Primer, 2018 & & & & & &
\end{tabular}


Tabel 4. Preferensi Konsumen terhadap Atribut Rasa Teh di Kabupaten Sukoharjo Tahun 2018

\begin{tabular}{|c|c|c|c|c|c|c|c|}
\hline \multirow[b]{2}{*}{ Atribut } & \multirow[b]{2}{*}{ Kategori Atribut } & \multicolumn{3}{|c|}{$\begin{array}{c}\text { Preferensi Teh } \\
\text { Seduh }\end{array}$} & \multicolumn{3}{|c|}{ Preferensi Teh Celup } \\
\hline & & $\begin{array}{c}\text { Urban } \\
(\%)\end{array}$ & $\begin{array}{c}\text { Sub } \\
\text { Urban } \\
(\%)\end{array}$ & $\begin{array}{c}\text { Desa } \\
(\%)\end{array}$ & $\begin{array}{c}\text { Urban } \\
(\%)\end{array}$ & $\begin{array}{c}\text { Sub } \\
\text { Urban } \\
(\%)\end{array}$ & Desa (\%) \\
\hline \multirow[t]{5}{*}{ Rasa } & Pahit & 19 & 12 & 9 & 9 & 9 & 3 \\
\hline & Sepat Sangat Pahit & 34 & 16 & 31 & 28 & 19 & 28 \\
\hline & Sepat Sedikit Pahit & 38 & 56 & 47 & 44 & 53 & 60 \\
\hline & Sepat & 9 & 16 & 13 & 19 & 19 & 9 \\
\hline & Total & 100 & 100 & 100 & 100 & 100 & 100 \\
\hline \multirow[t]{5}{*}{ Warna } & Merah Pekat Kehitaman & 19 & 12 & 13 & 19 & 13 & 3 \\
\hline & Coklat Kehitaman & 38 & 22 & 37 & 25 & 28 & 37 \\
\hline & Merah Kecoklatan & 31 & 47 & 34 & 40 & 40 & 41 \\
\hline & Merah Kekuningan & 12 & 19 & 16 & 16 & 19 & 19 \\
\hline & Total & 100 & 100 & 100 & 101 & 100 & 100 \\
\hline \multirow[t]{4}{*}{ Aroma } & Non Aromatik & 9 & 22 & 19 & 53 & 41 & 41 \\
\hline & Sedikit Harum & 50 & 53 & 50 & 38 & 53 & 50 \\
\hline & Sangat Harum & 41 & 25 & 31 & 9 & 6 & 9 \\
\hline & Total & 100 & 100 & 100 & 100 & 100 & 100 \\
\hline \multirow[t]{8}{*}{ Ukuran } & 100 & - & - & - & 16 & 13 & 0 \\
\hline & 80 & 6 & 16 & 16 & - & - & - \\
\hline & 60 & - & - & - & 18 & 28 & 25 \\
\hline & 50 & - & - & - & 16 & 28 & 53 \\
\hline & 40 & 81 & 65 & 78 & - & - & - \\
\hline & 10 & 13 & 19 & 6 & - & - & - \\
\hline & 8 & - & - & - & 50 & 31 & 22 \\
\hline & Total & 100 & 100 & 100 & 100 & 100 & 100 \\
\hline \multirow[t]{3}{*}{ Kepraktisan } & Mudah dalam Penyimpanan & & & & 38 & 22 & 25 \\
\hline & Mudah dalam Penyajian & & & & 62 & 78 & 75 \\
\hline & Total & & & & 100 & 100 & 100 \\
\hline \multirow[t]{3}{*}{ Jenis Kemasan } & Kardus & & & & 47 & 69 & 78 \\
\hline & Plastik & & & & 53 & 31 & 22 \\
\hline & Total & & & & 100 & 100 & 100 \\
\hline
\end{tabular}

Sumber : Analisis Data Primer, 2018

Tabel 5. Sikap Konsumen terhadap Atribut Teh di Kabupaten Sukoharjo Tahun 2018

\begin{tabular}{|c|c|c|c|c|c|c|c|c|}
\hline \multirow{2}{*}{ Atribut } & \multicolumn{4}{|c|}{ Teh Seduh } & \multicolumn{4}{|c|}{ Teh Celup } \\
\hline & $\mathbf{K}$ & $\mathbf{E}$ & $\mathbf{S}$ & $\mathbf{P}$ & $\mathbf{K}$ & $E$ & $\mathbf{S}$ & $\mathbf{P}$ \\
\hline Rasa & 3,86 & 4,83 & 18,67 & I & 3,56 & 4,23 & 15,06 & II \\
\hline Warna & 3,81 & 3,81 & 14,53 & IV & 3,77 & 3,63 & 13,67 & V \\
\hline Aroma & 3,78 & 4,08 & 15,44 & II & 3,6 & 3,98 & 14,34 & IV \\
\hline Ukuran & 4,39 & 3,5 & 15,38 & III & 4,22 & 3,52 & 14,84 & III \\
\hline Kepraktisan & - & - & - & - & 4,45 & 4,57 & 20,33 & I \\
\hline Jenis Kemasan & - & - & - & - & 4,19 & 3,22 & 13,47 & VI \\
\hline
\end{tabular}

